\title{
Comparative Evaluation of Ocimum sanctum and Calcium Hydroxide Mix as an Obturating Material in Deciduous Molars: An In Vivo Study
}

\author{
Shaili Agarwal ${ }^{1}$, Shailesh Gupta ${ }^{2}$, Sandeep Tandon ${ }^{3}$, Rinku Mathur ${ }^{4}$, Tripti S Rai ${ }^{5}$, Manish Kumar ${ }^{6}$, Ambika S Rathore ${ }^{7}$
}

\begin{abstract}
Aim and Objectives: To evaluate clinical and radiographic efficacy of a mix of $O$. sanctum (tulsi extract) and calcium hydroxide as an obturating material in primary molars and to compare these findings with commercially available iodoform with calcium hydroxide paste (metapex).

Materials and Methods: The present study was conducted on sixty children age group 4-7 years requiring multiple visit pulpectomy for their primary molars. The teeth selected were randomly divided into two groups. One group received Metapex and other group received Tulsi extract with calcium hydroxide as an obturating material. Clinical and radiographic evaluation were done between both the groups.

Results: There was no significant difference in the clinical and radiographic success rate between both the groups.

Conclusion: Tulsi extract with calcium hydroxide can be used as an obturating material in primary molars.

Keywords: Calcium hydroxide, Obturating material, Ocimum sanctum, Primary molars, Tulsi.

International Journal of Clinical Pediatric Dentistry (2020): 10.5005/jp-journals-10005-1840
\end{abstract}

\section{INTRODUCTION}

Primary dental arch is considered to be the natural space maintainer, thereby making it important to maintain its integrity, until their normal exfoliation. ${ }^{1-3}$

Tomie-Karovie and Jelinek ${ }^{4}$ and Edwards and Nord ${ }^{5}$ suggested that the disinfection of the root canal from polymicrobial flora determines the success of endodontic therapy.

Ample medicinal agents have been suggested as pulp therapy agents in primary teeth. Among the plants known for medicinal value, the plants of genus Ocimum (tulsi), has been suggested for its therapeutic potential. ${ }^{6-8}$

Tulsi is known for its orodental uses. Its leaves are quite effective in treating common oral infections. Thus, the present study aims to assess the radiological and clinical efficacy of a mix of Ocimum sanctum (tulsi extract) and calcium hydroxide as an obturating material in primary molars and to compare these findings with commercially available iodoform and calcium hydroxide paste (Metapex).

\section{Materials and Methods}

A total of 60 primary molars in children aged between 4 years and 7 years were selected from the outpatient clinic of the Department of Pediatric and Preventive Dentistry, RUHS College of Dental Sciences, Jaipur. After selection of patients clearance from the institutional ethical committee was obtained. The parents or guardians of the child were informed about the condition of the child's dentition. They were briefed about the treatment required including the advantage and risks associated if any. Participation in this study was at will and before the start of the study informed written consent was obtained from parents or guardian.
${ }^{1}$ Department of Prosthodontics, Pacific Dental College and Research Center, Udaipur, Rajasthan, India

${ }^{2}$ Department of Medical, Health and Family Welfare Government of Rajasthan, Jaipur, India

${ }^{3}$ Department of Pediatric and Preventive Dentistry, Government Dental College and Hospital, Jaipur, Rajasthan, India

4,5,7 Department of Pediatric and Preventive Dentistry, RUHS College of Dental Sciences, Jaipur, Rajasthan, India

${ }^{6}$ Department of Dentistry, Government Medical College and Hospital, Ratlam, Madhya Pradesh, India

Corresponding Author: Manish Kumar, Department of Dentistry, Government Medical College and Hospital, Ratlam, Madhya Pradesh, India, Phone: 8118858008, e-mail: drmanishagarwalmds@gmail.com

How to cite this article: Agarwal S, Gupta S, Tandon S, et al. Comparative Evaluation of Ocimum sanctum and Calcium Hydroxide Mix as an Obturating Material in Deciduous Molars: An In Vivo Study. Int J Clin Pediatr Dent 2020;13(6):617-621.

Source of support: Nil

Conflict of interest: None

The teeth which were selected for the study had the following clinical and radiographic criteria.

\section{Inclusion Criteria}

\section{Clinical Criteria}

- Restorable primary first and second mandibular molars.

- History of spontaneous pain with a deep carious lesion.

- Tenderness on percussion.

- Presence of abnormal mobility, i.e., mobility other than from normal exfoliation.

- Presence of abscess or fistula.

(-) Jaypee Brothers Medical Publishers. 2020 Open Access This article is distributed under the terms of the Creative Commons Attribution 4.0 International License (https://creativecommons.org/licenses/by-nc/4.0/), which permits unrestricted use, distribution, and non-commercial reproduction in any medium, provided you give appropriate credit to the original author(s) and the source, provide a link to the Creative Commons license, and indicate if changes were made. The Creative Commons Public Domain Dedication waiver (http://creativecommons.org/publicdomain/zero/1.0/) applies to the data made available in this article, unless otherwise stated. 


\section{Radiographic Criteria}

- Presence of radiolucency in the intraradicular and periradicular area not involving permanent tooth bud.

- Adequate bone coverage (at least two-thirds of one root).

- Absence of internal and external resorption.

- Presence of at least two-third root length.

\section{Exclusion Criteria}

\section{Clinical Criteria}

- Systemic illnesses, such as, congenital ischemic heart disease, leukemia.

- Children with special healthcare needs.

- Excessive tooth mobility.

- The unrestorable crown portion of the tooth.

\section{Radiographic Criteria}

- Pathological external root resorption.

- Internal resorption.

- Cysts associated with the primary tooth.

- Intraradicular radiolucency that communicates with the pulp chamber.

The teeth selected were randomly divided into two groups.

Both groups received their respective obturating material. Group I: lodoform with calcium hydroxide (Metapex). Group II: Tulsi extract with calcium hydroxide.

\section{Preparation of Calcium Hydroxide and Tulsi Extract Mixture}

Calcium hydroxide (one scoop) and tulsi extract (Shri Tulsi-three drops) was mixed to a hemogeneous consistency using a stainless steel spatula and a glass slab.

\section{Methodology}

The selected tooth was anesthetized using an inferior alveolar nerve block and the access cavity was prepared in accordance with the extent of the lesion.

Biomechanical and chemomechanical preparation was carried out using $\mathrm{K}$ and $\mathrm{H}$ files and appropriate irrigating solutions were used to debride necrotic pulp. Canals were dried using paper points. Then, the canals were obturated with Metapex group I and with the mixture of calcium hydroxide and tulsi extract in group II with the help of lentulospirals. Radiographic confirmation was done. Then, access cavity was restored with composite followed by stainless steel crowns.

Patients were recalled and the teeth of groups I and II were evaluated in 1-week, 3-month, and 6-month follow-up.

On follow-up visits, the evaluation was based on the (absence) following criteria:

\section{Clinical Criteria}

- Spontaneous pain,

- Tenderness.

- Abnormal mobility.

- Abscess/fistula.

\section{Radiographic Criteria}

- Intraradicular radiolucency.

- Periradicular radiolucency.
- Bone support.

- Internal resorption.

- Pathological external resorption.

Based on these clinical and radiographic criteria comparison was made between both materials.

The data obtained were subjected to statistical analysis.

\section{Results}

\section{Group I}

Following results were obtained in group I (Metapex).

\section{Clinical Criteria (Table 1)}

At 6-month recall, one tooth reported with pain. One tooth was tender till one week then no tooth was reported with tenderness at 3-month follow-up. At 6-month follow-up, two cases (6.7\%) were reported with tenderness.

Post-treatment no abnormal mobility or fistula was observed.

Radiographic Criteria (Table 2)

Intraradicular radiolucency increased in size in one case at 6-month follow-up. There was another case reported with intraradicular radiolucency at 6 months.

Periradicular radiolucency increased in size at 6 months in two cases.

Bone support was present in all the cases.

There was no internal resorption or pathological external root resorption.

\section{Group II}

Following results were obtained in group II (calcium hydroxide with tulsi extract).

\section{Clinical Criteria (Table 3)}

Spontaneous pain was present in all 30 cases before the treatment. After 1 week, pain was not present in any of the cases. At 3 months, one case was reported with mild pain which was relieved after an analgesic prescription. On 6-month recall, two cases were reported

Table 1: No. of cases with various clinical parameters at different followup visits in group I

\begin{tabular}{lllll}
\hline Clinical criteria & $\begin{array}{l}\text { Pre- } \\
\text { treatment }\end{array}$ & 1 week & 3 months & 6 months \\
\hline Spontaneous pain & $30(100 \%)$ & $0(0 \%)$ & $0(0 \%)$ & $1(3.3 \%)$ \\
Tenderness & $26(86.7 \%)$ & $1(3.3 \%)$ & $0(0 \%)$ & $2(6.7 \%)$ \\
Abnormal mobility & $0(0 \%)$ & $0(0 \%)$ & $0(0 \%)$ & $0(0 \%)$ \\
Abscess/fistula & $1(3.3 \%)$ & $0(0 \%)$ & $0(0 \%)$ & $0(0 \%)$ \\
\hline
\end{tabular}

Table 2: No. of cases with various radiographic parameters at different follow-up visits in group I

\begin{tabular}{lcccc}
\hline $\begin{array}{l}\text { Radiographic } \\
\text { criteria }\end{array}$ & $\begin{array}{l}\text { Pre- } \\
\text { treatment }\end{array}$ & 1 week & 3 months & 6 months \\
\hline $\begin{array}{l}\text { Intraradicular } \\
\text { radiolucency }\end{array}$ & $1(3.3 \%)$ & $1(3.3 \%)$ & $1(3.3 \%)$ & $2(6.7 \%)$ \\
$\begin{array}{l}\text { Periradicular } \\
\text { radiolucency }\end{array}$ & $0(0 \%)$ & $0(0 \%)$ & $1(3.3 \%)$ & $1(3.3 \%)$ \\
$\begin{array}{l}\text { Bone support } \\
\text { Internal resorption }\end{array}$ & $0(0 \%)$ & $0(0 \%)$ & $0(0 \%)$ & $0(0 \%)$ \\
$\begin{array}{l}\text { Pathological exter- } \\
\text { nal root resorption }\end{array}$ & $0(0 \%)$ & $0(0 \%)$ & $0(0 \%)$ & $0(0 \%)$ \\
\hline
\end{tabular}


with pain. The pain in one case got relieved after analgesics but in one case pain persisted even after analgesics so re-pulpectomy had to be done.

Tenderness was present in $83.3 \%$ of cases ( 25 out of 30 ) before the treatment. Two cases remained tender at 1-week follow-up. One case out of these two cases continued to be tender till 3-and 6-month follow-up too. At 6-month follow-up, two more cases were reported with tenderness.

No abnormal mobility was observed.

At 6-month follow-up, one case was reported with abscess and re-pulpectomy was done.

\section{Radiographic Criteria (Table 4)}

Intraradicular radiolucency of the same size remained in all four cases till 1 week and one more case was reported at 1-week follow-up period. At 3-month follow-up period, radiolucency disappeared in two cases but it still continued to persist in the other three cases in which it was present at 1-week follow-up period. In the same three cases, the radiolucency continued to be present at 6-month follow-up, and additionally one more case was reported with the intraradicular radiolucency.

Periradicular radiolucency was present in one case before the treatment. In this case, this radiolucency of the same size continued to be present at 1-week, 3-month, and 6-month follow-ups too. Two more cases were reported with periradicular radiolucency at 1-week follow-up. Out of these two cases, radiolucency disappeared

Table 3: No. of cases with various clinical parameters at different followup visits in group II

\begin{tabular}{lllll}
\hline & Pre- & & & \\
Clinical criteria & treatment & 1 week & 3 months & 6 months \\
\hline Spontaneous pain & $30(100.0 \%)$ & $00.0 \%$ & $13.3 \%$ & $26.7 \%$ \\
Tenderness & $25(83.3 \%)$ & $2(6.7 \%)$ & $1(3.3 \%)$ & $3(10 \%)$ \\
Abnormal mobility & $0(0 \%)$ & $0(0 \%)$ & $0(0 \%)$ & $0(0 \%)$ \\
Abscess/fistula & $1(3.3 \%)$ & $0(0 \%)$ & $0(0 \%)$ & $1(3.3 \%)$ \\
\hline
\end{tabular}

Table 4: No. of cases with various radiographic parameters at different follow-up visits in group II

\begin{tabular}{lcccc}
\hline $\begin{array}{l}\text { Radiographic } \\
\text { criteria }\end{array}$ & $\begin{array}{l}\text { Pre- } \\
\text { treatment }\end{array}$ & 1 week & 3 months & 6 months \\
\hline $\begin{array}{l}\text { Intraradicular } \\
\text { radiolucency }\end{array}$ & $4(13.3 \%)$ & $5(16.7 \%)$ & $3(10 \%)$ & $4(13.3 \%)$ \\
$\begin{array}{l}\text { Periradicular } \\
\text { radiolucency }\end{array}$ & $1(3.3 \%)$ & $3(10 \%)$ & $2(6.7 \%)$ & $1(3.3 \%)$ \\
$\begin{array}{l}\text { Bone support } \\
\begin{array}{l}\text { Internal } \\
\text { resorption }\end{array}\end{array}$ & $30(100 \%)$ & $30(100 \%)$ & $30(100 \%)$ & $30(100 \%)$ \\
$\begin{array}{l}\text { Pathological } \\
\text { external root } \\
\text { resorption }\end{array}$ & $0(0 \%)$ & $0(0 \%)$ & $0(0 \%)$ & $0(0 \%)$ \\
\hline
\end{tabular}

in one case at 3-month follow-up and in another case at 6-month follow-up. Bone support was present in all the cases before the treatment and at different follow-up periods.

\section{Comparison of Clinical and Radiographic Efficacy of Calcium Hydroxide and Tulsi Extract Mix with Metapex}

Clinical Criteria

The comparison of the efficacy of tulsi extract and Metapex for clinical criteria was done in two ways:

- Comparison of the two obturating materials based on the frequency distribution of cases at the four stages - pre-treatment, at 1 week, at 30 months, and at 6 months. The distributions were tested for equality using a Kolmogorov-Smirnov two-sample test at 0.05 significance level. For $p$ values $>0.05$, the inference is drawn that there is no statistically significant difference between the two sample distributions. A $p$ value $<0.05$ would indicate a statistically significant difference between the two sample distributions. A $p$ value $<0.01$ would indicate a statistically highly significant difference between the two sample distributions.

- Comparison of the two obturating materials based on the proportion of cases (\%) with respect to each of the clinical and radiographic criteria. The proportions were tested for equality using the two-sample $Z$ test of proportions at 0.05 significance level. For $p$ values $>0.05$, the inference is drawn that there is no statistically significant difference between the two sample proportions. A $p$ value $<0.05$ would indicate a statistically significant difference between the two sample proportions. A $p$ value $<0.01$ would indicate a statistically highly significant difference between the two sample proportions.

\section{Overall Clinical Success Rate (Table 5)}

Overall clinical success rates for tulsi with calcium hydroxide group and Metapex group were 90 and 93\%, respectively. There was no significant different clinical success rate between both the groups at the end of the study (i.e., 6 months) (Fig. 1).

\section{Overall Radiographic Success Rate (Table 6)}

Overall radiographic success rates for tulsi with calcium hydroxide group and Metapex group were 87 and 93\%, respectively. There was no significant different radiographic success rate between both the groups at the end of the study (i.e., 6 months) (Fig. 2).

\section{Discussion}

With predictable management strategies and a better understanding of the root canals morphology, performing pulpectomy procedures to preserve primary teeth has become the mainstay treatment modality. The rationale of pulpectomy is to preserve the functioning of the primary tooth by making it infection free until its normal exfoliation.

Table 5: Difference between Metapex and calcium hydroxide with tulsi extract mix in relation to the overall clinical success rate

\begin{tabular}{|c|c|c|c|c|c|}
\hline & Success & Failure & & & \\
\hline \multirow[t]{2}{*}{ Material } & Metapex & 28 & 2 & 30 & $p<0.01$, highly significant \\
\hline & Tulsi & 27 & 3 & 30 & $p<0.01$, highly significant \\
\hline \multicolumn{2}{|l|}{ Total } & 55 & 5 & 60 & \\
\hline \multicolumn{2}{|c|}{$\begin{array}{l}\text { (Metapex vs tulsi) Binomial test at } 0.05 \\
\text { significance level }-p \text { value }\end{array}$} & \multicolumn{2}{|l|}{1.00, not significant } & \multicolumn{2}{|c|}{1.00, not significant } \\
\hline
\end{tabular}




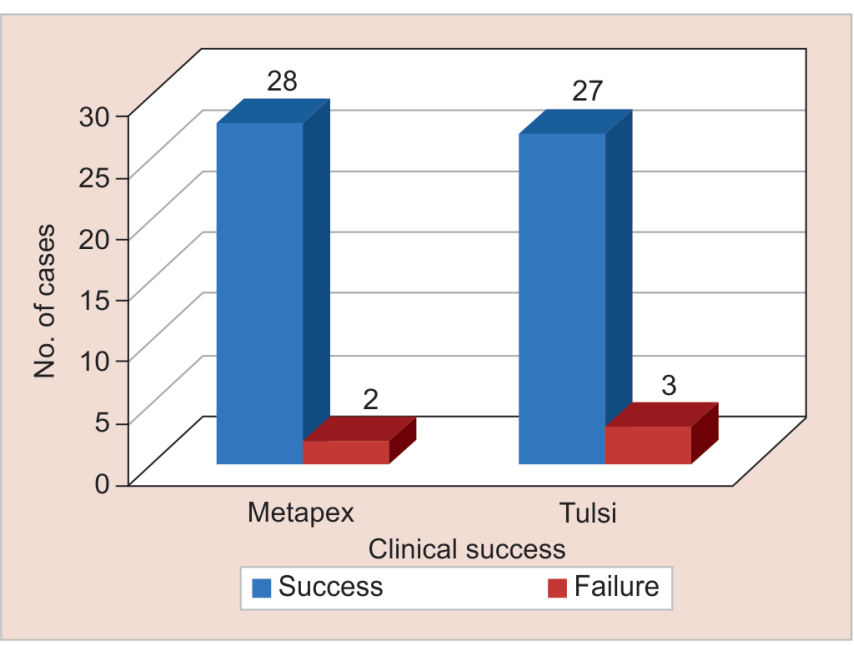

Fig. 1: The distribution of clinical success in group I and group II

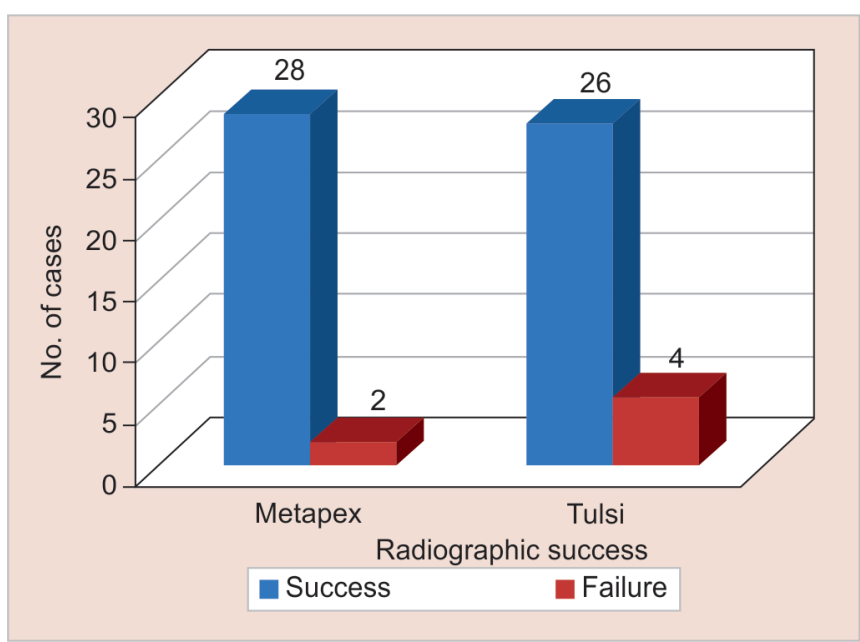

Fig. 2: The distribution of radiographic success in group I and group II

Table 6: Difference between Metapex and calcium hydroxide with tulsi extract mix in relation to the overall radiographic success rate

\begin{tabular}{|c|c|c|c|c|c|}
\hline & & \multicolumn{2}{|c|}{ Radiographic success } & \multirow[b]{2}{*}{ Total } & \multirow{2}{*}{$\begin{array}{l}\text { (Success vs failure) Binomial test at } \\
0.05 \text { significance level_- } p \text { value }\end{array}$} \\
\hline & & Success & Failure & & \\
\hline \multirow[t]{2}{*}{ Material } & Metapex & 28 & 2 & 30 & $p<0.01$, highly significant \\
\hline & Tulsi & 26 & 4 & 30 & $p<0.01$, highly significant \\
\hline Total & & 54 & 6 & 60 & \\
\hline \multicolumn{2}{|c|}{$\begin{array}{l}\text { (Metapex vs tulsi) Binomial test at } 0.05 \\
\text { significance level }-p \text { value }\end{array}$} & \multicolumn{2}{|c|}{0.892, not significant } & \multicolumn{2}{|c|}{0.688, not significant } \\
\hline
\end{tabular}

Pulpectomy of the deciduous teeth includes thorough debridement and obturation using a biocompatible material which would match the rate of resorption of the involved tooth, without damaging the succedaneous permanent tooth and its eruption.

Primary root resorption causes the position of the apical foramen to change continuously. Primary root canal anatomy is complex which further complicates the endodontic therapy. The causatives for the pulpal and periapical pathosis are the microorganisms and their by-products. The main objective of endodontic therapy is to disinfect from the canals and prevent subsequent reinfection, which further governs the success of endodontic treatment.

Various medicaments, such as ZOE, calcium hydroxide, Endoflas, and iodoform combin ation formulations have been used to date with varying success rates, ranging between 70 and $90 \% .^{9-11}$

Lately, extracts of various medicinal plants have also been widely suggested for their orodental uses. Phytomedicine (use of medicinal herbs for treatment) for oral disorders, such as dental caries and periodontal disease, has also been well practiced in traditional medicine of Indian, Egyptian, Greek, and Chinese civilizations.

In search of herbal compounds with broader and more effective antibacterial action in endodontics, tulsi extract showed significant antimicrobial activity when tested in vitro.

In consideration with other herbal medicines, tulsi is available in adequate amount, easy to procure, economic, and has been in use over centuries and possesses minimal side effects, hence its long-term use can be recommended.

Agarwal et al. ${ }^{12}$ showed that tulsi extract demonstrated antimicrobial activity against Streptococcus mutans and has the maximum antimicrobial potential at the $4 \%$ concentration level.
Gadiyar et al. ${ }^{13}$ carried out a study to determine the antimicrobial effect of $O$. sanctum $L$. against caries causing microorganisms $S$. mutans and Lactobacillus acidophilus and found out that the MIC of ethanolic extract of $O$. sanctum $L$. against $S$. mutans and L. acidophilus was $2.5 \%(25 \mathrm{mg} / \mathrm{mL})$ and $10 \%(100 \mathrm{mg} / \mathrm{mL})$, respectively.

Prabhakar et al. ${ }^{14}$ carried out an in vivo study to evaluate and compare the antibacterial efficacy of $O$. sanctum L. leaves (tulsi) extract with saline solution as an intracanal irrigant against dentinal bacterial biofilms and concluded that $4 \%$ tulsi extract can be considered as a potential irrigant in contemporary pediatric endodontics.

Many in vitro studies have shown tulsi extract to be very effective against microbes causing root canal infection. Based on these in vitro studies we carried out this study to evaluate the efficacy of calcium hydroxide and tulsi (O. sanctum) extract mix as an obturating material in primary molar teeth.

In this study, calcium hydroxide and iodoform paste was used as a control group. Calcium hydroxide has been used as a root canal filling material in primary teeth with accountable success. ${ }^{15}$ The antibacterial property, tissue compatibility, and resorbable nature make it reasonable for use in primary teeth.

lodoform is also commonly used in root canals of primary teeth. lodoform is can be used singular or in combination with other materials. It is bacteriocidal, non-irritant, has good radiopacity, its non-shrinkage and insoluble properties make it a material of choice. ${ }^{16}$ It is a resorbable paste, it resorbs faster when compared to ZOE. ${ }^{17}$

Reyes and Reina ${ }^{18}$ and Kubota et al. ${ }^{19}$ suggested that the combination of calcium hydroxide with iodoform as an obturating material gives excellent clinical, radiographic, and histological results. 
Machida ${ }^{20}$ found that calcium hydroxide iodoform paste (Vitapex) resorbed faster when compared with the rate of root resorption. The study concluded that calcium hydroxide and iodoform mixture to be an almost ideal obturating material for primary teeth.

The present study used various clinical and radiographic criteria for evaluation of the success of pulpectomies. Clinical criteria were an absence of spontaneous pain, tenderness on percussion, abnormal mobility, presence of abscess/fistula. Radiographic criteria were the absence of intraradicular and periradicular radiolucencies, bone support, internal resorption, and pathological external root resorption.

Preoperative spontaneous pain was present in all 30 cases of group I (Metapex) and all 30 cases of group II (tulsi extract) before the treatment.

In this study, overall clinical success rates for group I (Metapex) and group II (tulsi) were 93 and 90\%, respectively. And overall radiographic success rates for group I (Metapex) and group II (tulsi) were 93 and $87 \%$, respectively. The clinical and radiographic success had no significant difference between both the groups, suggesting the use of both the agents as root canal obturating options in teeth.

\section{Conclusion}

The results in the study showed that endodontic therapy of primary teeth using calcium hydroxide and tulsi mix as an obturating material had a very good clinical and radiographic success rate and was equally comparable to calcium hydroxide and iodoform mix (Metapex).

However, to ascertain the efficacy of this obturating material prospective studies including clinical and histological evaluation with follow-up till tooth exfoliation should be carried out.

\section{References}

1. Prabhakar AR, Sridevi E, Raju OS, et al. Endodontic treatment of primary teeth using combination of antibacterial drugs: an in vivo study. J Indian Soc Pedod Prevent Dent - Supplement 2008. 5-8.

2. Takushige T, Cruz EV, Moral AA, et al. Endodontic treatment of primary teeth using a combination of antibacterial drugs. Int Endod J 2004;37(2):132-138. DOI: 10.1111/j.0143-2885.2004.00771.x.

3. Cohen M, Burns RC. Path ways of pulp. 8th ed., St. Louis: Mosby Inc; 2002.
4. Tomie-Karovie K, Jelinek E. Comparative study of the bacterial flora in the surroundings, the root canals and sockets of primary molars. Int Dent J 1971;21:375-388.

5. Edwards S, Nord GE. Identification and characterization of microorganisms isolated from infected primary teeth. J Int Assoc Dent Child 1972;3:15-18.

6. Sen P. Therapeutic potential of tulsi: from experience to facts. Drug News Views 1993;1:15-21.

7. Gupta SK, Prakash J, Srivastav S. Validation of traditional claim of tulsi, Ocimum sanctum Linn. as a medicinal plant. Indian J Exp Biol 2002;40:765-773.

8. Chopra RN, Nayer SI, Chopra IC. Glossary of Indian Medicinal plants. New Delhi: CSIR; 1956.

9. Mortazavi M, Mesbahi M. Comparison of zinc oxide eugenol and Vitapex for root canal treatment of necrotic primary teeth. Int J Paediatr Dent 2004;14(6):417-424. DOI: 10.1111/j.1365263X.2004.00544.x.

10. Martin DM, Crabb HS. Calcium hydroxide in root canal therapy - a review. Br Dent J 1977;142(9):277-283. DOI: 10.1038/sj.bdj.4803904.

11. Foreman PC, Barnes I. A review of calcium hydroxide. Int Endodon J 1990;23(6):283-297. DOI: 10.1111/j.1365-2591.1990.tb00108.x.

12. Agarwal P, Nagesh L, Murlikrishnan. Evaluation of the antimicrobial activity of various concentrations of tulsi (Ocimum sanctum) extract against Streptococcus mutans - an in-vitro study. J Dent Res 2010;21(3):357-359.

13. Gadiyar A, Ankola V, Rajpurohit L. Evaluation of antimicrobial activity of Ocimum sanctum L. (Tulsi) extract against Streptococcus mutans and Lactobacillus acidophilus - an in-vitro study. Int J Health Sci Res 2017;17(4):224-228.

14. Prabhakar AR, Krishnamurthy VVR, Chandrashekar Y. Ocimum sanctum as an intracanal irrigant in contemporary pediatric endodontics - an in-vivo study. Int Res Oral Health Med Res 2015;2(4):6-9.

15. Rosendahl R, Weinert Grodd A. Root canal treatment of primary molars with infected pulps using calcium hydroxide as a root canal filling. J Clin Pediatr Dent 1995;19:255-258.

16. Castagnola L, Orlay HG. Treatment of gangrene of the pulp by the walkoff method. Br Dent J 1952;93:93-102.

17. Barker BC, Lockett BC. Endodontic experiments with resorbable pastes. Aust Dent J 1971;16(6):364-372. DOI: 10.1111/j.1834-7819.1971. tb03433.x.

18. Reyes $A D$, Reina ES. Root canal treatment in necrotic primary molars. J Pedod 1989;14:36-40.

19. Kubota K, Golden BE, Penugonda B. Root canal filling materials for primary teeth. A review of literature. ASDC J Dent Child 1992;59: 225-227.

20. Machida Y. A clinico-radiographical study of root canal filling in the deciduous teeth with Vitapex. Japanese J Pedod 1978;16:360-365. 